\title{
A novel pattern of oculocerebral malformation
}

Brian J Clark, William R Lee, David Doyle, Reynir Arngrimsson, John L Tolmie, John B P Stephenson

\begin{abstract}
Aims/background-To report a novel pattern of oculocerebral malformation related to the group of diseases characterised by cobblestone lissencephaly.

Methods-By means of a case report with specialist descriptions of the novel neuropathological and ophthalmic pathology features.
\end{abstract}

Results-The patient, born to healthy consanguineous parents, presented in the neonatal period with jaundice, convulsions, and macrocephaly. Computed tomography demonstrated hydrocephalus and abnormal cerebral gyration. Ophthalmic examination revealed severe myopia and segments of retinal atrophy. Cytogenetic investigation revealed a balanced reciprocal translocation $(46, X X, t(5 p 11 ; 19 q 13.1))$ that was inherited from the mother and was present in several normal relatives. Mild short stature and profound mental handicap were evident. The child died aged 7 years. At necropsy the brain showed 'cobblestone' (type II) lissencephaly. Cerebellar cortical architecture was abnormal and the brain stem lacked cerebral peduncles, basis pontis, and pyramids. Biopsies of skeletal muscles were normal. The ocular abnormalities included discrete sectors of retina of varying thickness with disordered neuronal lamination and gliosis. The optic nerve was gliotic and contained few nerve fibres. The anterior iris surface was studded with cellular stromal nodules which appear to be melanocytic in nature.

Conclusion-Retinal dysgenesis occurs in the group of syndromes with 'cobblestone lissencephaly', the best known being Walker-Warburg syndrome. In this case, relatively long survival, lack of muscular dystrophy, and novel ocular pathology distinguish it from the other diagnoses in this group of syndromes. We suggest this child was affected by a distinct and novel oculocerebral syndrome.

(Br F Ophthalmol 1997;81:470-475) report here a child affected by ocular and cerebral malformations which resemble those
The development of the brain and the eye are very closely linked, with many parallels in both the morphological changes ${ }^{1}$ which take place and the molecular events ${ }^{2-5}$ which are thought to underlie the processes. It is not surprising, therefore, that malformations of the eye and central nervous system frequently coexist. ${ }^{6} \mathrm{We}$

\author{
The Fraser of Allander \\ Unit, Royal Hospita \\ for Sick Children, \\ Glasgow \\ J B P Stephenson \\ Correspondence to: \\ Dr B J Clark, Ophthalmic \\ Pathology Laboratory, \\ Pathology Department \\ Western Infirmary, \\ Dumbarton Road, Glasgow \\ G11 6NT. \\ Accepted for publication \\ 11 March 1997
}

present in the eye-brain syndromes associated with 'cobblestone' lissencephaly (previously known as type II lissencephaly). ${ }^{7}$ However, novel features in the eye and other clinical findings suggest this child's condition represents a hitherto unreported pattern of oculocerebral disease.

\section{Case report and methods}

The patient (Fig 1) was the second child born to Scottish parents who are first cousins, whose firstborn daughter was normal. The pregnancy was uneventful and delivery occurred at 42 weeks' gestation by caesarean section for fetal distress. Birth weight was $4.35 \mathrm{~kg}$ (approximately the 90th centile) and head circumference was $38.5 \mathrm{~cm}$ (greater than the 90th centile). General physical examination revealed a non-dysmorphic infant who had a small 'port wine' haemangioma on her right shoulder.

In the neonatal period she developed jaundice, requiring phototherapy, and convulsions. Electroencephalogram showed giant $(1 \mathrm{mV})$ spikes. Neuroradiological examination showed wide sutures and fontanelles, thickening of the

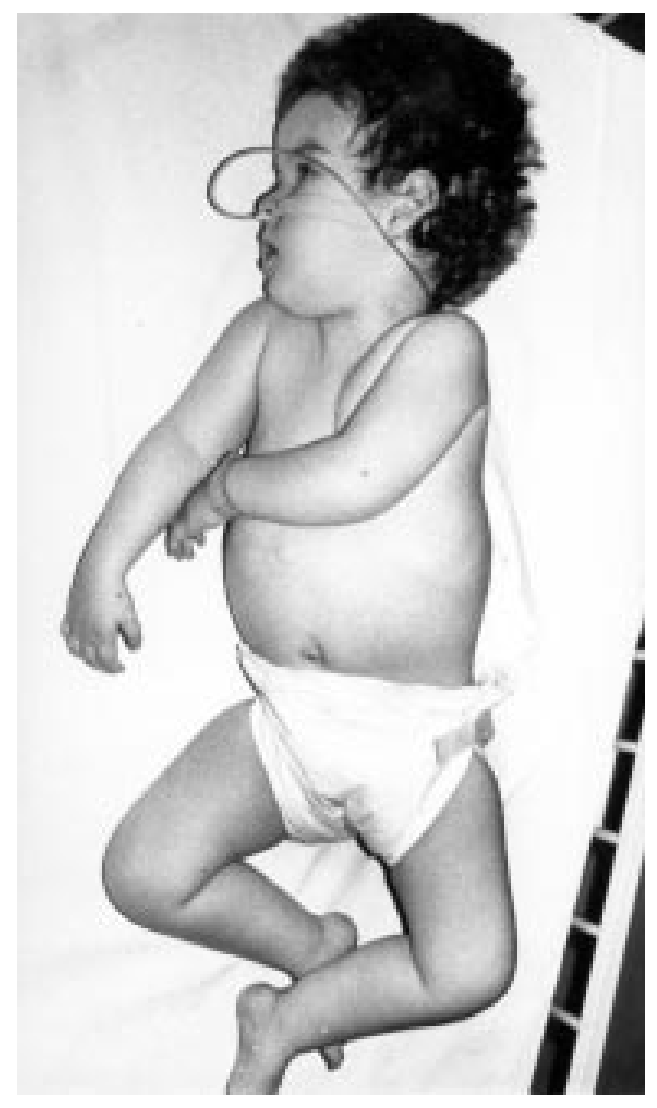

Figure 1 Clinical photograph of the external appearance of the child. 

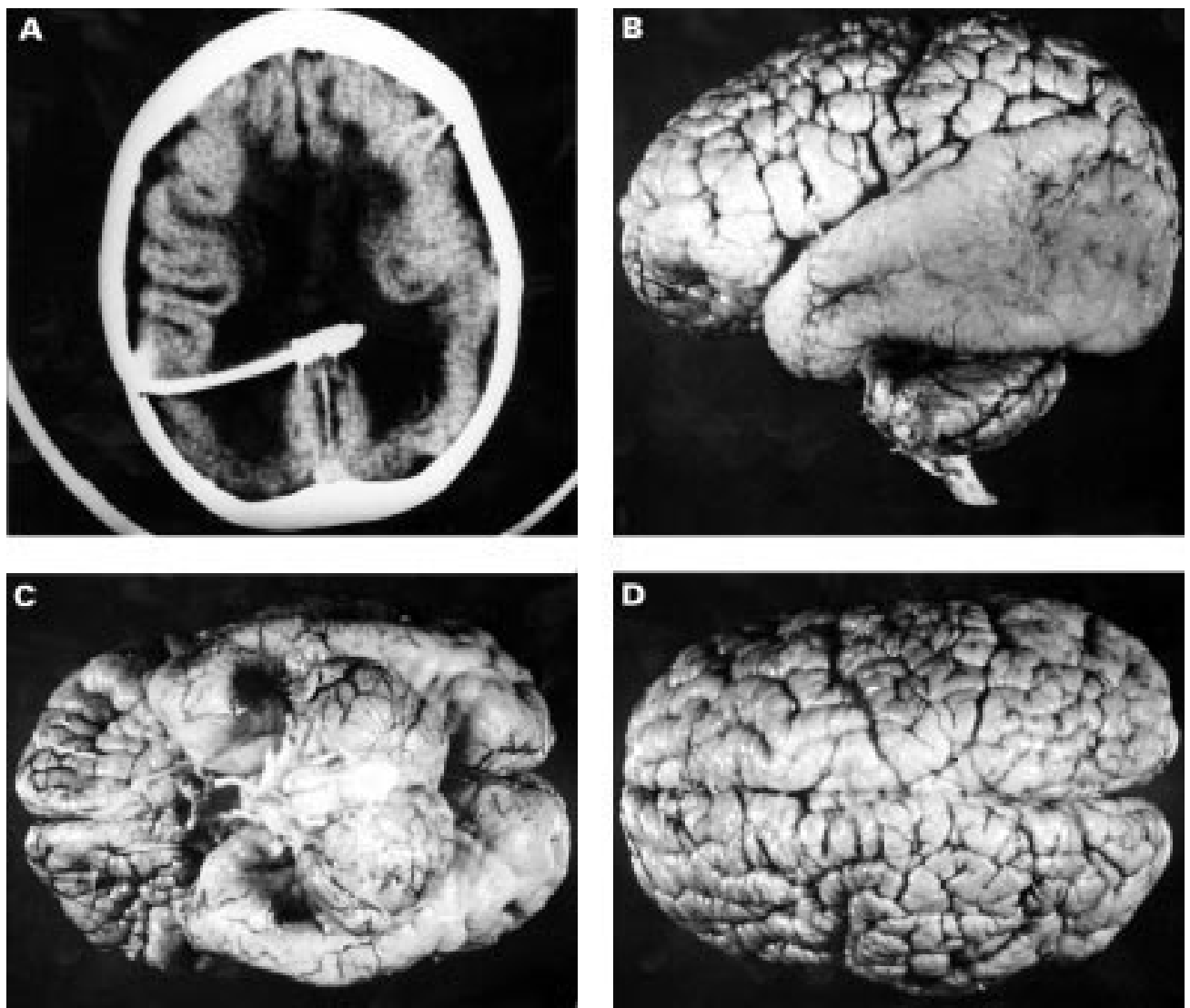

Figure 2(A) Horizontal computed tomography scan of head showing shunted hydrocephalus, abnormal gyration, absence of the septum pellucidum, and hypodense periventricular white matter. Macroscopic views of the whole fixed brain; (B) left lateral view; (C) inferior view; (D) superior view. The abnormal sulcal and gyral pattern is evident with loss of markings in the temporal and occipital regions, coarsening of gyri in the frontal region, and polymicrogyria in the parietal region.

cranial vault, and a very small pituitary fossa. Computed tomography scanning confirmed hydrocephalus and showed large, hypodense periventricular areas (Fig 2). The scan appearances also suggested pachygyria, widening of the Sylvian fissures, absence of the septum pellucidum and corpus callosum, and cerebellar hypoplasia.

Clinical ophthalmic examination showed that the child had no definite fixation and rapid

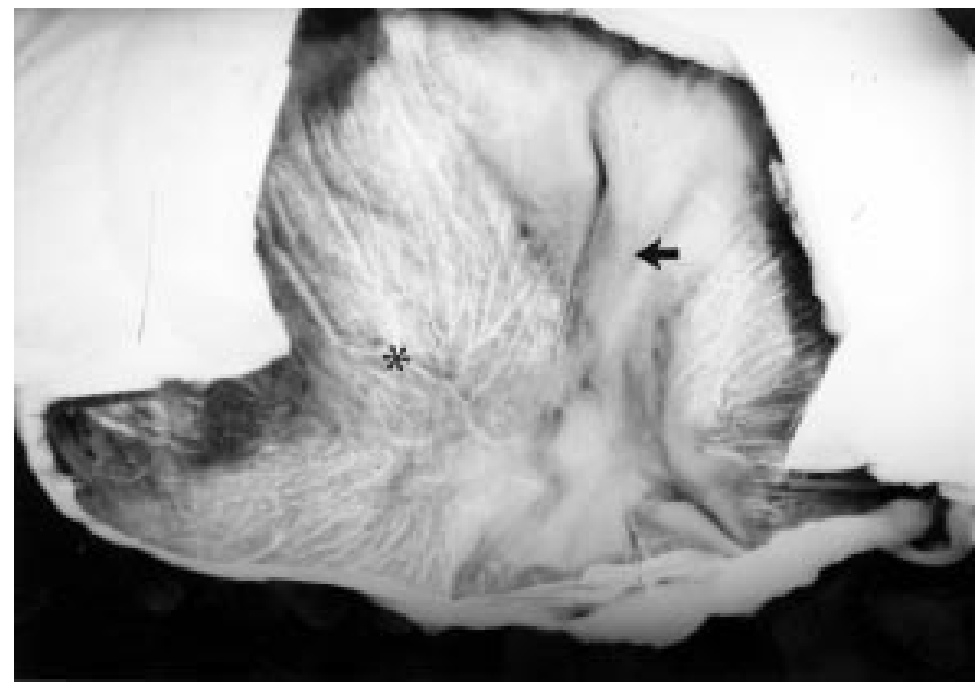

Figure 3 Macroscopic view of the posterior pole of the opened fixed globe. A large area of the retina is severely atrophic ( ${ }^{*}$ ) with a band of abnormally thickened retina (arrow) extending outwards from the optic nerve head. conjugate eye movements. Both eyes were highly myopic. The corneas were clear and the anterior chambers and intraocular pressures were normal. Peripheral lens opacities were noted. The retinas were markedly abnormal with diminished sectoral pigmentation-some areas appearing completely atrophic. The discs were hypoplastic. Electroretinograms were reduced and visual evoked responses were of very low amplitude.

Biochemical, microbiological, and serological tests carried out on blood and CSF revealed no evidence of congenital or embryopathic infection. Cytogenetic analysis revealed a balanced translocation (46,XX,t $(5 \mathrm{p} 11$;19q13.1)) but an identical translocation was present in the mother and several maternal relatives, all of whom were normal.

The patient had profound mental handicap and milder growth retardation such that, by 5 years of age when she developed precocious puberty, supine length was less than the 3 rd centile and weight on the 25 th centile for age. The patient died aged 7 years 4 months.

A systemic necropsy, with specialist neuropathological and ophthalmic pathological opinions, was conducted. Neuropathological examination included macroscopic brain cut with appropriate histology, histological examination of multiple skeletal muscle samples and preparations to show innervation. For ophthalmic pathology, the eyes were fixed in $10 \%$ neutral buffered formalin. Horizontal 


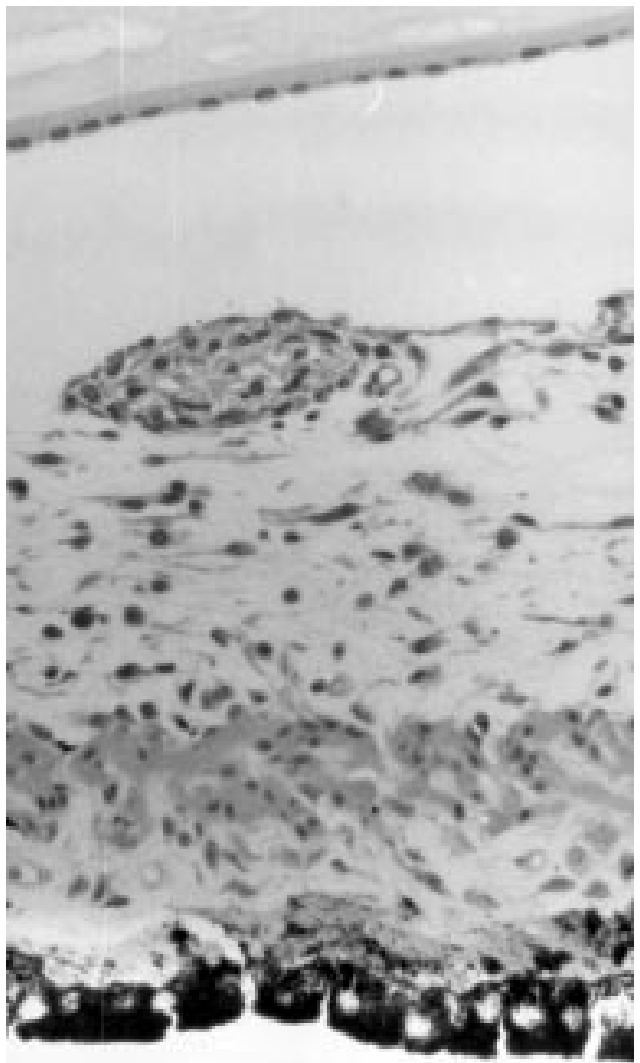

Figure 4 Micrograph of the iris showing discrete cellular aggregates in the anterior stroma at the anterior iris surface. Haematoxylin and eosin, $\times 105$.

blocks, to include the pupil and optic nerve head (PO blocks), were processed for conventional paraffin wax embedding, sectioning, and light microscopy. Sections cut at $5 \mu \mathrm{m}$ were stained using standard methods with haematoxylin and eosin, periodic acid Schiff (PAS), Masson's trichrome, Gordon and Sweet's method for reticulin, the Masson-Fontana method for melanin and Perl's method for iron. Additionally, immunocytochemical staining,

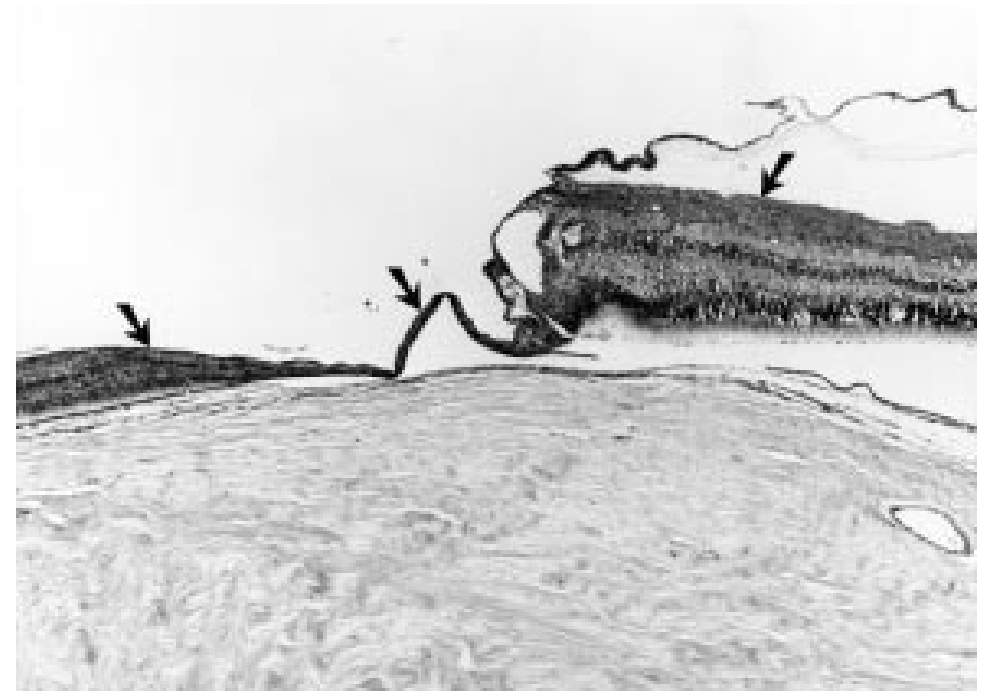

Figure 5 Low power micrograph of the retina showing three discretely different sectors of abnormality (arrows). Note the presence of a preretinal membrane. Haematoxylin and eosin, $\times 27$. using either the peroxidase-antiperoxidase method or the avidin-biotin-complex (ABC) method, was conducted for the primary antibodies outlined below.

\section{Results}

Systemic necropsy confirmed a growth retarded, although well nourished, child with features of precocious puberty. Bone age was in accordance with chronological age.

Neuropathological examination confirmed that the brain was markedly abnormal. There were large areas of agyria with small areas of polymicrogyria (Fig 2). Hydrocephalus was evident with dilatation of all ventricles. A small corpus callosum was present. The cerebral cortex was abnormal at all sites, with virtually no suggestion of neuronal lamination, the appearance being of complete cellular disorganisation. It appeared that the white matter had no clear organisation and aberrant bundles of myelinated fibres were present in the subpial parts of the cortex. The ependyma was submerged into the brain substance because of a layer of glial tissue lining the ventricles. The brain stem lacked cerebral peduncles, basis pontis, and pyramids. The cerebellum was formed and the vermis was present. However, the cerebellar cortex was of abnormal structure-bands of germinal tissue were present close to the fourth ventricle, there were ectopic collections of Purkinje cells, and cells of the molecular layer were distributed among the cells of the granular layer. Multiple biopsies from different skeletal muscles sampled post mortem did not show any significant microscopic abnormality. Preparations to show innervation showed normal intramuscular nerve bundles and normal branching of axons. The end plates were normal.

The eyes collapsed after fixation. Macroscopically, they appeared to have normal anterior segments. Large sectors of retinal atrophy were evident and the discs were hypoplastic (Fig 3). Microscopic examination confirmed that the corneas, aqueous drainage systems, and anterior chambers were normal. The irides had cellular aggregates on their anterior stromal surfaces (Fig 4), the nature of which was investigated immunohistochemically. The cells within the aggregates stained with antisera against vimentin (Immunon), S100 protein (Dako), and HMB45 (Dako), but did not stain with neurofilament (Immunon), glial fibrillary acidic protein (GFAP) (Immunon), CD45 (Immunon), AE1/3 (Euro Diagnostics), QBend10 (Euro Diagnostics), CAM 5.2 (Becton Dickson), CD68 (Dako), or Leu7 (Becton Dickson). This pattern suggests melanocytic differentiation although melanin was not detectable within the cells. A few ectopic ciliary processes were present originating from the iris roots but the ciliary bodies were otherwise normal. The anterior lens cortices were liquefied and contained bladder cells.

The most extreme pathology was present in the retinas. There were sectoral abnormalities of varying severity. Sectors of thick retina bordered sectors of totally atrophic and gliotic retina or areas of disordered retina (Fig 5). 
A

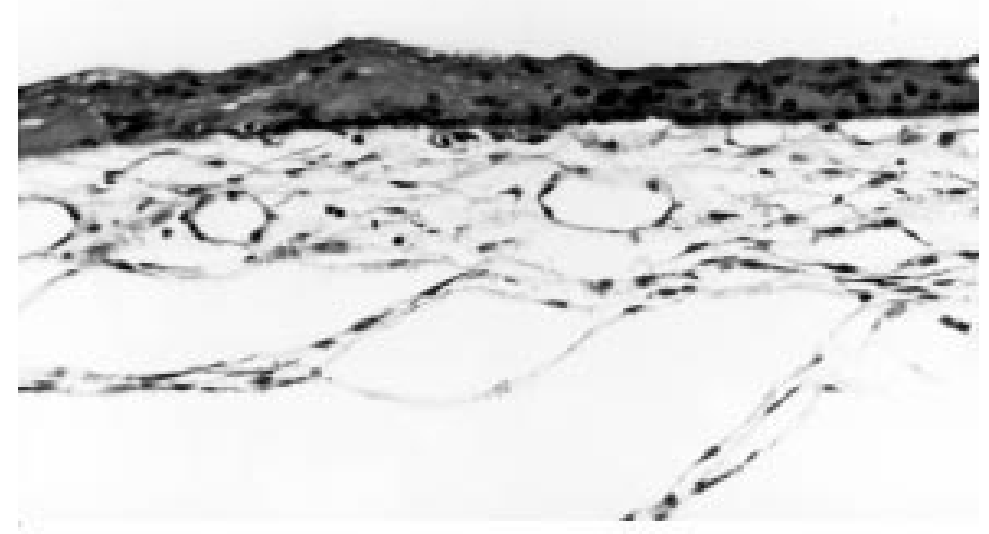

B

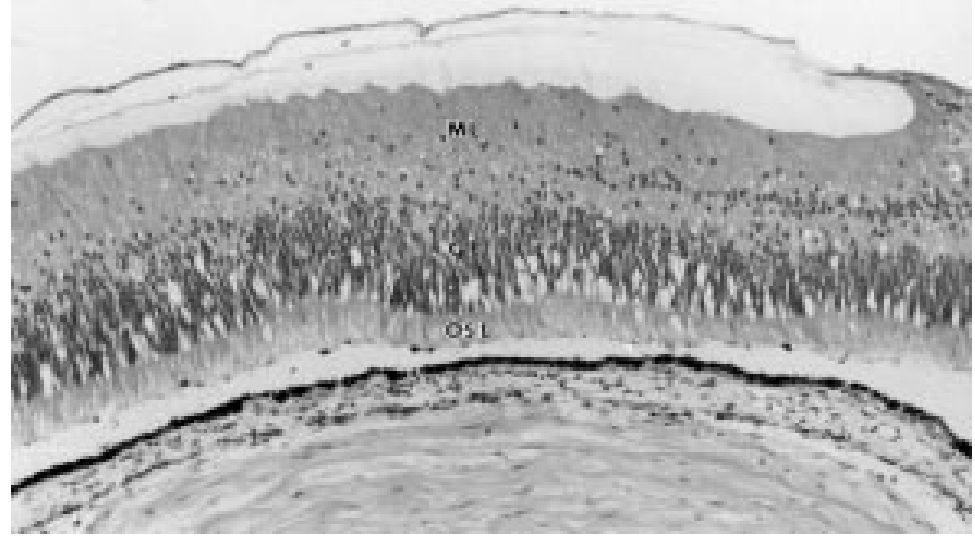

Figure 6 Micrographs of abnormal retina. (A) The retina is thinned and severely gliotic. Haematoxylin and eosin, $\times 255$. (B) The retina shows severe immaturity of lamination with only a photoreceptor outer segment layer (OSL), a germinal layer (GL), and a marginal layer $(M L)$. Haematoxylin and eosin, $\times 75$.

These various sectors were arranged indiscriminately. In some sectors the retina was thinned and severely gliotic (Fig 6A) whereas in others the structure approximated normal. Hypoplastic zones appeared to have deficient neuronal lamination. There was a resemblance at some sites to immature stages of prenatal retinal development. One feature, however, which differed from incompletely formed retina was the presence of well formed photoreceptor outer segments in areas devoid of full retinal lamination. This was particularly evident in the periphery where both rods and cones were present in retina with an overall cellular architecture consisting only of a 'germinal' neuroepithelial layer and a 'marginal'-like layer (Fig 6B). Better formed areas of retina were distorted due to overlying preretinal membranes. Throughout the retina there were very few ganglion cells and nerve fibres were very reduced in number both in the retina and within the optic nerve. There was no detectable myelination of the optic nerve. The inner retina and optic nerve contained a large number of glial cells detected by anti-GFAP immunohistochemical staining. Islands of ectopic glia were embedded within the optic nerve meninges. At no point, in the multiple sections studied, were neuroepithelial 'rosettes' seen. The retinal pigment epithelium, choroid, and sclera were within normal limits for myopic eyes.

\section{Discussion}

This child was affected by an ultimately fatal constellation of cerebral and ocular abnormalities reminiscent of the malformations present in the group of syndromes characterised by 'cobblestone lissencephaly" (formally known as type II lissencephaly). The conditions included in this group are Walker-Warburg syndrome (WWS), ${ }^{8-15}$ muscle-eye-brain (MEB) disease, ${ }^{16-18}$ cerebro-oculo-muscular dystrophy (COMD), ${ }^{19}$ and cerebro-ocular dysplasia-muscular dystrophy syndrome (COD-MD syndrome). While some authors regard these conditions as a single entity with phenotypic variability, this view is contentious. ${ }^{20}{ }^{21}$ Certainly, these syndromes all appear to have autosomal recessive inheritance with a large proportion of reported cases being born to consanguineous parents as in this case. WWS and MEB disease have been considered allelic, ${ }^{7}$ as has WWS and Fukuyama muscular dystrophy, the latter condition being mapped to $9 \mathrm{q} 31-33,{ }^{22-24}$ but more detailed gene mapping information is required to clarify the syndromic status of these conditions.

In arguing that these syndromes represent different manifestations of a single disease, Dobyns et $a l^{20}$ highlighted features common to all reported cases which were regarded as diagnostic criteria. These included type II lissencephaly, cerebellar malformation, retinal malformation, and congenital muscular dystrophy. Diagnostic criteria for various conditions with cobblestone lissencephaly were subsequently refined in an attempt to overcome continued controversy about the relation between the separately described entities, ${ }^{7}$ but this case illustrates some continuing difficulties. The neuropathological features that we observed are consistent with cobblestone lissencephalynamely, mixed agyria (but with a finely pebbled surface), pachygyria and polymicrogyria, white matter abnormalities, enlarged ventricles, and brainstem and cerebellar hypoplasia. The striking retinal pathology found in this case is broadly consistent with 'retinal malformation' although, to our knowledge, the pattern of segmental variation in retinal maturity, with superimposed areas of complete atrophy and gliosis, has not been described. The nearest pattern reported in the literature consists of regular segmental 'leopard spots' reported by Barth et al. ${ }^{25}$ Unfortunately, in our case there was no record of blood creatine kinase value, but absence of clinically apparent weakness and lack of histological evidence of muscular dystrophy means an important diagnostic feature of both MEB and WWS, namely, congenital muscular dystrophy, was missing. ${ }^{7}$ Muscle was found to be normal in another rare entity designated Dobyns-Patton-Stratton 
syndrome (cobblestone lissencephaly with normal eye and muscle $)^{7}$ but the eyes in the few patients with this condition were normal both clinically and electrophysiologically. The atypical retinal features, normal skeletal muscles, unusually long survival of 7 years (median survival for WWS of 4 to 9 months, only $5-10 \%$ of patients surviving $>5$ years), and the observation of previously unreported cellular nodules on the anterior iris stroma all suggest that this case was not affected by the usual type of WWS. Ocular pathology typical of WWS ${ }^{7-15}$ includes complete retinal detachment with dysplasia, persistent posterior hyperplastic vitreous, chorioretinal colobomata, optic nerve hypoplasia, microphthalmia, Peter's anomaly, incomplete angle recession with glaucoma, and cataract. It is interesting that the retinal abnormality found in WWS is described as dysplasia with rosettes. Although, by definition, the term dysplasia indicates no more than abnormal prenatal retinal development, the term as commonly used tends to infer the presence of rosettes. ${ }^{26}{ }^{27}$ It is usually present where developing retina is detached from the adjacent retinal pigment epithelium and this is thought to disturb a crucial developmental relation between these two derivatives of the optic cup. ${ }^{27}$ While strictly the term is appropriate in this case, the absence of rosettes may make the term dysgenesis preferable in this case to prevent ambiguity.

Iris nodules have not been described previously in the lissencephaly syndromes. Nodules of various types have been described in other conditions such as Down's syndrome, ${ }^{28}{ }^{29}$ the iris naevus (Cogan-Reese) syndrome, ${ }^{30}$ Klinefelter's syndrome, ${ }^{31}$ Zellweger syndrome, ${ }^{32}$ and neurofibromatosis. ${ }^{33-35}$ Of these, the Lisch nodules of neurofibromatosis, ${ }^{33-35}$ which represent melanocytic hamartomata on the anterior iris stromal surface, most closely resemble the nodules seen in this case.

A possible pathogenesis of the cerebral and retinal pathology seen in this case is suggested by apparent immaturity of cerebral and cerebellar cortical lamination and striking similarity of some parts of the retina to immature phases of retinal development. These features suggest failure of neuroblast migration and differentiation from the primitive neuroepithelium resulting in disordered or incomplete lamination and cellular ectopia. ${ }^{7}$ It is interesting to speculate that this may have a basis in abnormal guidance by radial glial fibres during development and it seems possible that neuroblasts which have landed in abnormal sites may then have responded to inappropriate environments by increased cell death resulting in atrophy and secondary gliosis. It is of note that the territories affected in this case are only those parts of the neuroepithelium with a neuronal lineage - the abnormalities in the eye stop abruptly at the ora serrata with derivatives of the inner optic cup anterior to the ora, and the RPE, being apparently normal by light microscopy. This observation, and the sectoral nature of the severity of retinal disease, may suggest that a defect exists in a gene that is responsible for neuronal cell lineage and pattern formation within the neuroepithelium, such as PAX $6 .{ }^{36}$ This observation may indicate future genomic sites worthy of examination to identify the molecular defect responsible.

We are grateful to Mr J A W Ralston his valuable contribution to the histology and Mrs S Cameron for her photographic assistance. Dr A A M Gibson, FRCPath, conducted the necropsy.

1 McCartney, ACE. Embryological development of the eye. In: Garner A, Klintworth GK, eds. Pathobiology of ocular disease, a dynamic approach. 2nd ed. New York: Marcel Dekker, 1994:1255-84.

2 Beebe DC. Homeobox genes and vertebrate eye development. Invest Ophthalmol Vis Sci 1994;35:2897-900.

3 Hanson I, Van Heyningen V. Pax6: more than meets the eye. Trends Genet 1995;11:268-72.

4 Oliver G, Mailhos A, Wehr R, Copeland NG, Jenkins NA, Gruss P. Six 3, a murine homologue of the sine oculis gene, demarcates the most anterior border of the developing neural plate and is expressed during eye development. Development 1994;121:4045-55.

5 Tassabehji M, Read AP, Newton VE, Harris R, Balling R, Gruss P, et al. Waardenburg's syndrome patients have mutations in the human homologue of the Pax-3 paired box gene. Nature 1992;355:635-6.

6 Torczynski, E. Developmental anomalies of the eye. In: Garner A, Klintworth GK, eds. Pathobiology of ocular disease, a dynamic approach. 2nd ed. New York: Marcel Dekker, 1994:1285-344

7 Dobyns WB, Truwit CL. Lissencephaly and other malformations of cortical development: 1995 update. Neuropediatrics 1995;26:132-47.

8 Warburg M. Hydrocephaly, congenital retinal nonattachment, and congenital falciform fold. Am $\mathcal{f}$ Ophthalmol 1978;85:88-94.

9 Winter RM, Garner A. Hydrocephalus, agyria, pseudoencephalocele, retinal dysplasia, and anterior chamber anomalies. $\mathcal{F}$ Med Genet 1981;18:314-7.

10 Levine RA, Gray DL, Gould N, Pergament E, Stillerman ML. Warburg syndrome. Ophthalmology 1983;91:1600-3.

11 Dobyns WB, Kirkpatrick JB, Hittner HM, Roberts RM, Kretzer FL. Syndromes with lissencephaly. II WalkerWarburg and cerebro-oculo-muscular syndromes and a new syndrome with type II lissencephaly. Am f Med Genet new syndrome with

12 Murphy KJ, PeBenito R, Storm RL, Ferretti C, Liu DPC. Walker-Warburg syndrome. Case report and literature review. Ophthalmic Paediatr Genet 1989;11:103-8.

13 Denis D, Gambarelli D, Luciani A, Ayme S, Philip N, Saracco JB. Walker-Warburg syndrome: a report of three cases. Ophthalmologica 1993;207:113-6.

14 Gerding H, Gullotta F, Kuchelmeister K, Busse H. Ocular findings in Walker-Warburg syndrome. Child's Nerv Syst 1993;9:418-20

15 Rodgers BJ, Vanner LV, Pai GS, Sens MA. Walker-Warburg syndrome: report of three affected sibs. Am f Med Genet 1994;49:198-201.

16 Santavuori P, Somer H, Sainio J, Rapola S, Kruus T, Nikitin $\mathrm{T}$, et al. Muscle-eye-brain disease (MEB). Brain Dev 1989; 11:147-53.

17 Santavuori P, Pihko H, Sainio K, Lappi M, Somer H, Haltia $\mathrm{M}$, et al. Muscle-eye-brain disease and Walker-Warburg M, et al. Muscle-eye-brain disease and W
syndrome. Am f Med Genet 1990;36:371-2.

18 Dobyns WB, Pagon RA, Curry CJR, Greenberg F. Regarding Walker-Warburg syndrome and muscle-eye-brain disease. Am F Med Genet 1990;36:373-4. (Response to Santavuori et al.)

19 Sanders DGM, Mooy CM. Ocular findings in cerebroocular-myopathy syndrome (COMS). A possible role for growth factors? Int Ophthalmol 1993; 17: 223-8.

20 Dobyns WB, Pagon RA, Armstrong D, Curry CJR, Greenberg F, Grix A, et al. Diagnostic criteria for WalkerWarburg syndrome. Am f Med Genet 1989;32:195-210.

21 Laverda AM, Battaglia MA, Drigo P, Battistella PA, Casara GL, Suppiej A, et al. Congenital muscular dystrophy, brain and eye abnormalities: one or more clinical entities? Child's Nerv Syst 1993;9:84-7.

22 Fukuyama Y, Osawa M, Suzuki H. Congenital progressive muscular dystrophy of the Fukuyama type-clinical, muscular dystrophy of the Fukuyama type-clinical, 3enetic and

23 Todd T, Segawa Y, Nomura Y, Nonaka I, Masuda T, Ishihara T, et al. Localization of a gene for Fukuyama type congenital muscular dystrophy to chromosome 9q31-33. Nature Genetics 1993;5:283-6.

24 Toda T, Yoshioka M, Nakahori Y, Kanazawa I, Nakamura Y, Nakagome Y. Genetic identity of Fukuyama-type congenital muscular dystrophy and Walker-Warburg syndrome. Ann Neurol 1995;37:99-101.

25 Barth RA, Pagon RA, Bunt-Milam AH. 'Leopard spot' retinopathy in Warburg syndrome. Ophthalmic Paediatr Genet 1986;7:91-6.

26 Lahav M, Albert DM. Clinical and histopathologic classification of retinal dysplasia. Am $\mathcal{F}$ Ophthalmol 1973;75:648-67.

27 Silverstein AM, Osburn BI, Prendergast RA. The pathogenesis of retinal dysplasia. Am f Ophthalmol 1971;72:13-21. 
28 Duke-Elder S. Part 2. Congenital deformities. In DukeElder S, ed. System of ophthalmology. Vol III Normal and abnormal development. London: Henry Kimpton, 1964 1136-7.

29 Shapiro MB, France TD. The ocular features of Down's syndrome. Am f Ophthalmol 1985;99:659-63.

30 Eagle RC, Font RL, Yanoff M, Fine BS. The iris naevus (Cogan-Reese) syndrome: light and electron microscopic observations. Br f Ophthalmol 1980;64:446-52.

31 Klintworth GK. Genetically determined disorders affecting the eye. In: Garner A, Klintworth GK, eds. Pathobiology of ocular disease, a dynamic approach. 2nd ed. New York: Marcel Dekker, 1994:811-38.

32 Garner A. Metabolic disorders involving metals. In: Garner A, Klintworth GK, eds. Pathobiology of ocular disease, a dynamic approach. 2nd ed. New York: Marcel Dekker, 1994:1137-45.

33 Lewis RA, Riccardi VM. von Recklinghausen neurofibromatosis. Incidence of iris hamartomata. Ophthalmology 1981;88:348-54.

34 Williamson TH, Garner A, Moore AT. Structure of Lisch nodules in neurofibromatosis Type 1. Ophthalmic Paediatr Genet 1991;12:11-7.

35 Ragge NK, Falk RE, Cohen WE, Murphree AL. Images of Lisch nodules across the spectrum. Eye 1993;7:95-101.

36 Schmahl W, Knoedlseder M, Favor J, Davidson D. Defects of neuronal migration and the pathogenesis of cortical malformations are associated with Small eye (Sey) in the Neuropathol 1993;86:126-35. 